\title{
Tratamiento de los gliomas mediante virus oncolíticos: revisión de la literatura
}

\author{
I. Arrese; P. González; P. Miranda; A. Pérez-Núñez; B. Pascual y R.D. Lobato
}

Servicio de Neurocirugía. Hospital Universitario 12 de Octubre. Madrid.

\section{Resumen}

Los gliomas son los tumores cerebrales primarios más frecuentes. Los tratamientos tradicionales se han basado en la cirugía, la radioterapia y la quimioterapia. Pese al avance en estas terapias, el pronóstico de estos tumores ha permanecido casi constante durante los últimos años. Dada la ausencia de mejoría en el pronóstico, los últimos avances en técnicas de biología molecular han abierto un nuevo campo de investigación para el desarrollo de nuevos tratamientos, y dentro de ellos, se ha evaluado el uso de virus oncolíticos en diferentes ensayos. En esta revisión discutimos los avances ocurridos en el uso de terapias basadas en estos agentes anticancerosos.

PALABRAS CLAVE: Virus oncolíticos. Glioma. Biología molecular.

Oncolytic viral terapy of gliomas: review of the literature

\section{Summary}

Gliomas are the most frequent primary tumors of the brain. The standard treatment includes surgery, radiotherapy and chemotherapy, but the outcomes of patients with these tumors have remained nearly unchanged for past years. Hopefully, recent advances in molecular biology are rising new clinical expectation for patients with brain tumors. Among the novel techniques in this new field of research a new field of research, the use of oncolytic viruses has been explored in different trials during last years. In the present review we analyze the advances in the understanding of the oncolytic viral therapy of gliomas.

KEY WORDS: Oncolytic viruses. Glioma. Molecular biology

Recibido: 20-05-04. Aceptado: 22-06-04

\section{Introducción}

Los gliomas son los tumores primarios más frecuentes del sistema nervioso central y, pese al continuo esfuerzo empleado en su estudio, el pronóstico se ha mantenido prácticamente invariable durante las últimas décadas. Las terapias sobre las que se ha sustentado su tratamiento han sido la cirugía, la radioterapia y, en menor medida, la quimioterapia, pero con el empleo de estas técnicas los beneficios obtenidos han resultado muy limitados. Por ello, los gliomas han sido los tumores del sistema nervioso central sobre los que se han realizado un mayor número de estudios a fin de aplicar nuevos métodos de tratamiento. A este respecto, el fulgurante desarrollo de la biología molecular y la inmunología han abierto las puertas a nuevas terapias que, aunque todavía en ciernes, constituyen la principal esperanza de incrementar la supervivencia de los pacientes con estos tumores. Una de estas terapias se basa en la capacidad oncolítica de determinados virus, los cuales han sido estudiados y experimentalmente aplicados de manera creciente a lo largo de los últimos años. En esta revisión tratamos de aclarar la situación actual de las terapias basadas en el uso de virus oncolíticos, explicando los fundamentos en los que se basan estas terapias y exponiendo los ensayos clínicos realizados hasta el momento.

\section{Virus oncolíticos}

Podríamos definir como virus oncolíticos a aquellos agentes virales que pueden replicarse selectivamente en las células tumorales, lisándolas y liberando nuevos agentes con capacidad, así mismo, de infectar células adicionales en la masa tumoral ${ }^{16}$. Pese a que el mejor desarrollo de estas terapias se ha producido a lo largo de los últimos años, ya desde principios del pasado siglo se conoce la posible actividad oncolítica de algunos virus, cuando Dock $^{11}$ y Depace $^{10}$ reportaron dos casos de regresiones tumorales en relación con los virus influenza y de la rabia respectivamente. Posteriormente, se han reportado, a lo largo del pasado siglo, diversos casos de regresiones tumorales asociadas a infecciones virales, como la viruela ${ }^{27}$, herpes 
Tabla 1

Agentes creados mediante técnicas de ingeniería genética con potencial actividad oncolítica contra los gliomas

\begin{tabular}{lll} 
Virus original & Agente & Modificación realizada \\
\hline Herpesvirus & G207 & Delección de $\gamma_{1} 34.5$ y $\mathrm{U}_{\mathrm{L}} 39$ \\
& HSV1716 & Delección de $\gamma_{1} 34.5$ \\
Adenovirus & ONIX-015 & Delección de E1B \\
& $\Delta 24$ & Delección de ElA \\
& $\Delta 24-\mathrm{RGD}$ & Delección de ElA e inserción del péptido RGD \\
& CB1 & Delección de ElA y ElB
\end{tabular}

Poliovirus

PV1(RIPO)

Replicons

Virus vacuna

rVV-p53

rVV-mIL2

rVV-mIL 12

rVV-2-12
Sustitución de la región IRES por elementos de rinovirus humanos

Delección de la cápside viral (P1)

Virus replicante con gen de p53

Virus replicante con gen de IL-2

Virus replicante con gen de IL-12

Virus replicante con genes de IL-2 e IL-12 zoster $^{5,63}$, virus de la hepatitis ${ }^{65}$ o sarampión ${ }^{4}$.

Pero además de lo observado en casos esporádicos, la idea de utilizar los virus como agente terapéutico del cáncer no es nueva. En los años 20 se realizaron ensayos que mostraban la replicación de ciertos virus en tumores inducidos experimentalmente en animales de laboratorio ${ }^{54}$, y posteriormente, en los años 50, se comenzaron a realizar los primeros estudios en humanos. De estos estudios, el que tuvo mayor repercusión fue el realizado en 1956 por el "National Cancer Institute" utilizando adenovirus salvajes en el tratamiento del carcinoma de cérvix ${ }^{55}$, en el cual más de la mitad de las pacientes tratadas mostraron regresiones tumorales, pero de duración muy limitada. Estos resultados iniciales desesperanzadores provocaron el abandono de estas líneas de investigación, pero cuando años después, las nuevas técnicas de biología molecular han podido dotar artificialmente a los virus de mayor capacidad para infectar y destruir selectivamente las células tumorales (Tabla 1), han aparecido en la literatura un creciente número de estudios que utilizan estos agentes con modificaciones artificiales $^{51}$. En esta revisión discutiremos los avances ocurridos en el conocimiento de los virus oncolíticos, analizando aquéllos que por sus características se consideran candidatos a jugar un papel importante en el tratamiento de los gliomas (Tabla 2).

\section{Virus Herpes Simple (VHS)}

El VHS presenta algunas características que le hacen especialmente interesante como agente oncolítico. Al ser un virus muy bien conocido, están identificados los genes que le confieren neurotoxicidad y los que presentan actividad oncolítica. Además, una gran parte de su genoma puede ser reemplazado sin que el virus pierda su capacidad replicativa. Por último, es el único virus de los que se ha usado en terapia oncológica cuya infección puede ser tratada mediante antivirales, por lo que el manejo de potenciales infecciones sistémicas se hace más seguro ${ }^{43,53}$.

El primer VHS modificado genéticamente, con el fin de ser utilizado como agente oncolítico, fue el $d l s p t k$. Se trataba de un VHS mutante al que le habían provocado la delección del gen de la timidina-kinasa para aumentar su selectividad hacia las células tumorales. Este agente fue ensayado en gliomas inducidos en roedores ${ }^{41}$; sin embargo, nunca se realizaron ensayos en humanos debido a la toxicidad que presentaba cuando se empleaban altos títulos, y a la resistencia a las terapias antivirales que le confería la delección del gen de la timidina-kinasa. Este mismo grupo 
Tabla 2

Mecanismo de acción de los agentes oncolíticos potncialmente útiles en el tratamiento de los gliomas

Herpesvirus:

G207

HSV 1716

Adenovirus:

ONYX-015

$\Delta 24$

$\Delta 24-\mathrm{RGD}$

CB1

Reovirus:

Reolysin (C)

Poliovirus:

PV1(RIPO)

Replicons

Virus vacuna:

rVV-p53

rVV-mIL2

rVV-mIL12

rVV-2-12

Parvovirus:

parvovirus $\mathrm{H}-1$
Ausencia de neurovirulencia $\longrightarrow$ infección selectiva tumor

Ausencia de neurovirulencia $\rightarrow$ infección selectiva tumor

Selectividad hacia células con mutaciones p53

Selectividad hacia células con mutaciones $\mathrm{pRB}$

Selectividad hacia células con mutaciones $\mathrm{pRB}$ e independencia de receptores RCAs

Selectividad hacia células con mutaciones p53 y pRB

Selectividad hacia células con sobrerregulación Ras

Selectividad hacia células que expresen el receptor CD155

Invasión celular sin posterior infección vecina

Inducción de apoptosis

Estimulación de la inmunidad

de investigación, focalizó su interés posteriormente en otro gen del VHS: el $\gamma_{1} 34.5$. Este gen produce el denominado ICP34.5, cuya función es romper los mecanismos de defensa de la célula ante la infección uniéndose a la fosfatasa-1. Por lo tanto, eliminando este gen se conseguiría dotar al virus de selectividad hacia la célula tumoral, pues las neuronas normales tendrían capacidad para defenderse; además, se mantendría la susceptibilidad del virus a ser atacado por los antivirales, pues no se alteraría su producción de timidita-kinasa. Basándose en esta idea se crea en 1995 el G207, que resulta tras provocar en un VHS una doble delección: a) delección del $\gamma_{1} 34.5$ para conferir al virus selectividad hacia las células tumorales y b) delección del $\mathrm{U}_{\mathrm{L}} 39$, que al ser un gen que codifica una larga subunidad de la RNA-reductasa viral, reduce enormemente la probabilidad de que el virus mute hacia la forma salvaje y pueda provocar así patologías por infección herpética ${ }^{42}$. Tras los primeros estudios sobre animales, en los que se evaluó su eficacia y seguridad ${ }^{6,31,39,58}$, en el año 2000 se hace el primer estudio sobre humanos ${ }^{40}$. Este ensayo fase I, encaminado a evaluar la seguridad terapéutica, se realizó sobre 21 pacientes con recurrencias de gliomas malignos a los que se les administró intratumoralmente dosis escalonadas del virus. Todos los pacientes debían haber sufrido recidivas comprobadas en pruebas de imagen tras haber recibido un tratamiento estándar de radioterapia con cirugía o biopsia. Este estudio resultó exitoso, pues con ninguna de las dosis empleadas se produjeron signos de toxicidad, de encefalitis, 
ni hubo que emplear drogas antiherpéticas. Además, pese a que el diseño del estudio era de fase I, y por consiguiente no estaba encaminado a evaluar la eficacia del tratamiento, los autores reportaron ciertos indicios que sugerían la probable utilidad del tratamiento, como la reducción del volumen tumoral en 8 de los pacientes tratados. Debido a estos esperanzadores resultados, está en curso un ensayo fase $1 \mathrm{~b} / 11$, dirigido también por la Universidad de Alabama, a fin de validar la seguridad y evaluar la efectividad del tratamiento en pacientes con recidivas de gliomas de alto grado. En la fase Ib de este estudio, los pacientes recibirán intracranealmente una dosis más alta que las previamente administradas en humanos. La fase II del ensayo sólo se llevará a cabo si no hay problemas de seguridad, y el objetivo de esta fase será evaluar la supervivencia a los 6 meses tras la administración intratumoral del G207, para lo cual se administrará el $15 \%$ de la dosis esterotáxicamente y, dos días después, se resecará el tumor administrando el resto de la dosis en el lecho de la resección.

Casi al mismo tiempo que se publicaban los datos del ensayo fase I con el mutante G207 en EEUU por Market y cols. ${ }^{40}$, desde Glasgow se publicaban los de otro ensayo fase I, realizado con el mutante HSV1716 ${ }^{48}$. A este mutante sólo se le ha inducido la defección de las dos copias del gen $\gamma_{1} 34.5$, probándose su selectividad en ensayos con roedores $^{61}$. Además, se realizaron otros ensayos animales que demostraron su posible eficacia terapéutica, disminuyendo el tamaño tumoral y aumentando la supervivencia ${ }^{34,37,47,49}$. En el ensayo realizado en Glasgow se evaluó la seguridad del tratamiento con HSV1716, administrando el agente esterotáxicamente sobre nueve pacientes con recidiva de astrocitomas malignos tratados con terapias standard. Se observó que en ningún paciente se dieron signos de encefalitis ni hubo que asociar tratamiento antiviral. Posteriormente, este mismo grupo realizó un segundo ensayo sobre 12 pacientes con recidivas de tumores gliales malignos a los que se les administró intratumoralmente el mutante y, a los pocos días, se les resecó el tumor ${ }^{47}$. En este segundo ensayo, no sólo se volvió a comprobar la nula toxicidad del tratamiento, sino que además se evidenció la replicación viral en las células tumorales. Futuros estudios deberán de encaminarse a demostrar la eficacia del tratamiento de gliomas con HSV1716.

\section{Adenovirus}

Como ya comentamos con anterioridad, los adenovirus fueron de los primeros virus en los que se estudió la capacidad oncolítica, cuando en los años 50 fueron probados como posible tratamiento para los tumores de cérvix uterino $^{55}$. Sin embargo, es a finales de la pasada década cuando, debido a los avances en las técnicas de biología molecular, se pudo modificar su genotipo, y con ello, incrementar su especificidad antitumoral. Los adenovirus salvajes tienen la capacidad de inactivar el antioncogen p53, el cual provoca la apoptosis de la célula cuando ésta es infectada, impidiendo así la replicación del virus (Fig. 1). Por medio de una proteína que se codifica en el gen E1B del genoma del virus eluden la acción del p53, y con ello, evitan que la célula se autodestruya. Basándose en esta idea, Bischoff y cols. crearon una mutación del adenovirus denominada ONYX- $015^{3}$, la cual consiste en provocar la delección del gen E1B para que el virus se replique selectivamente en aquellas células cuyo gen p53 esté alterado: sólo aquellas células con alteraciones del p53 serán infectadas, mientras que las células que lo tengan intacto podrán defenderse autodestruyéndose ${ }^{25}$. Dado que múltiples tumores de la economía presentan mutaciones del antioncogen p53, el ONYX-015 puede ser, hipotéticamente, un agente terapéutico eficaz para todos ellos. Aunque el estudio original de Bischoff y cols. ${ }^{3}$ se realizó sobre ratones portadores de células de carcinoma de cérvix humano, los tumores en los que se han realizados ensayos clínicos con ONYX-015 son los carcinomas de cabeza y cuello, los tumores de aparato digestivo y los de ovario ${ }^{17,26,29,33,36,38,44,45,50,62}$.

En lo que respecta a los gliomas, dado que el antioncogén p53 está implicado en la génesis molecular de algunos de ellos, se ha estudiado su posible utilidad terapéutica. En Francia, Geoerger y cols. han obtenido buenos resultados utilizando ONYX-015 como tratamiento único o en combinación con radioterapia en ratones a los que se les ha inoculado en el tejido subcutáneo células derivadas de gliomas humanos portadores de la mutación del p53 $3^{18,19}$. Por otro lado, Chiocca está actualmente llevando a cabo en el Massachusetts General Hospital un ensayo fase I para valorar la seguridad de la administración intracerebral de ONYX-015. En este ensayo participan pacientes con recidivas de gliomas malignos a los que se les introduce en el lecho tumoral ONYX-015 tras la resección quirúrgica de los mismos.

Otra diana molecular que ha sido planteada en el tratamiento de los gliomas mediante adenovirus oncolíticos es el supresor tumoral pRB. Hay una región genética de los adenovirus, la ElA, que está encargada de inactivar al gen de supresión tumoral pRB de la célula infectada, y así inducir a la célula a que entre en el ciclo de proliferación celular. Por lo tanto, basándonos en la misma idea que antes hemos expuesto para explicar el mecanismo de acción del ONYX-015, si se modifica la región E1A del adenovirus, este nuevo virus mutado sólo podrá infectar a aquellas células que tengan el gen pRB alterado, mientras que las células que conservan este gen supresor se defenderán ${ }^{1}$. Fueyo y cols., en el Anderson Cancer Center de Huston, describieron un mutante de adenovirus al que generaron una defección de 24 pares de bases en la región ElA, denominándolo $\Delta 24^{15}$. Este mutante pierde con ello la capacidad 


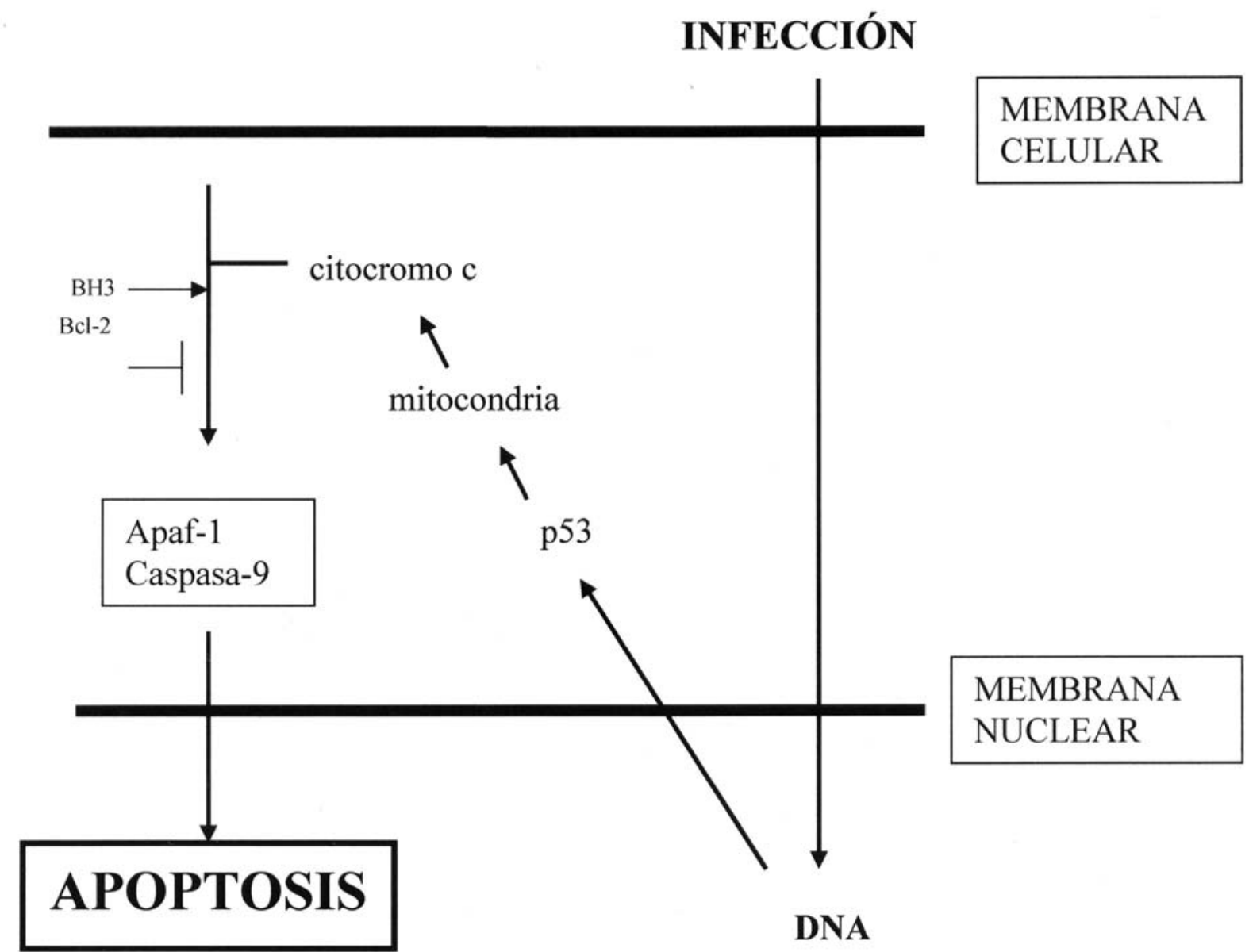

Figura 1. Mecanismo de acción del p53, provocando la apoptosis en respuesta a la alteración del ADN que ha inducido la infección viral.

de unirse al pRB, y por lo tanto, se convierte en selectivo para aquellas células con alteraciones en dicho gen. Los autores demostraron sobre células de gliomas humanos que el $\Delta 24$ se replicaba y lisaba las células tumorales ${ }^{14}$.

Pero los adenovirus presentan un problema que limita su infectividad, y éste es la escasez de receptores de coxsackievirus y adenovirus (RCAs) que presentan algunas líneas tumorales. A fin de superar esta limitación, Suzuki y cols. generaron una modificación que hacía al adenovirus independiente de los RCAs, y con ello aumentaban su infectividad ${ }^{59}$. Así, se crea el mutante $\Delta 24-R G D$, que consiste en: a) defección de 24 pares de bases en la región ElA para conferirle selectividad hacia las células con alteraciones del pRB ; b) inserción del péptido RGD que le permite anclarse a las integrinas de la célula directamente, sin necesidad de unirse a los RCAs. En Holanda, Lamfers y cols. ${ }^{35}$ han probado con éxito el uso de inyecciones intratumorales de $\Delta 24-R G D$ en ratones a los que se les había inoculado subcutáneamente células de gliomas humanos ; además, en este estudio, demuestran que la radiación a bajas dosis aumenta sustancialmente la efectividad del tratamiento. Por otro lado, un reciente ensayo del grupo de Huston ha comprobado, también administrando estos adenovirus intratumoralmente en gliomas portados por ratones, que la infectividad de los virus que poseen el RGD es 6 veces superior a los que no lo poseen, y que el RGD además les confiere mayor capacidad citopática y replicativa, aumentando significativamente la supervivencia de los ratones en estudio $^{13}$.

Uniendo las dos dianas moleculares principales que han sido estudiadas, GómezManzano y cols., también del grupo de Huston, han publicado muy recientemente los resultados obtenidos con un nuevo mutante de adenovirus: el CB1 ${ }^{20}$. A este virus se le ha incorporado una doble delección de 24 pares de bases de la región ElA y de 903 pares de bases de la región E1B, por lo que mostrará selectividad hacia las células que tengan alterados los genes supresores p53 o pRB. Este mutante ha sido probado intratumoralmente en ratones a los que se les inoculó gliomas humanos a nivel intracraneal. Tras una dosis única los ratones mostraron un 


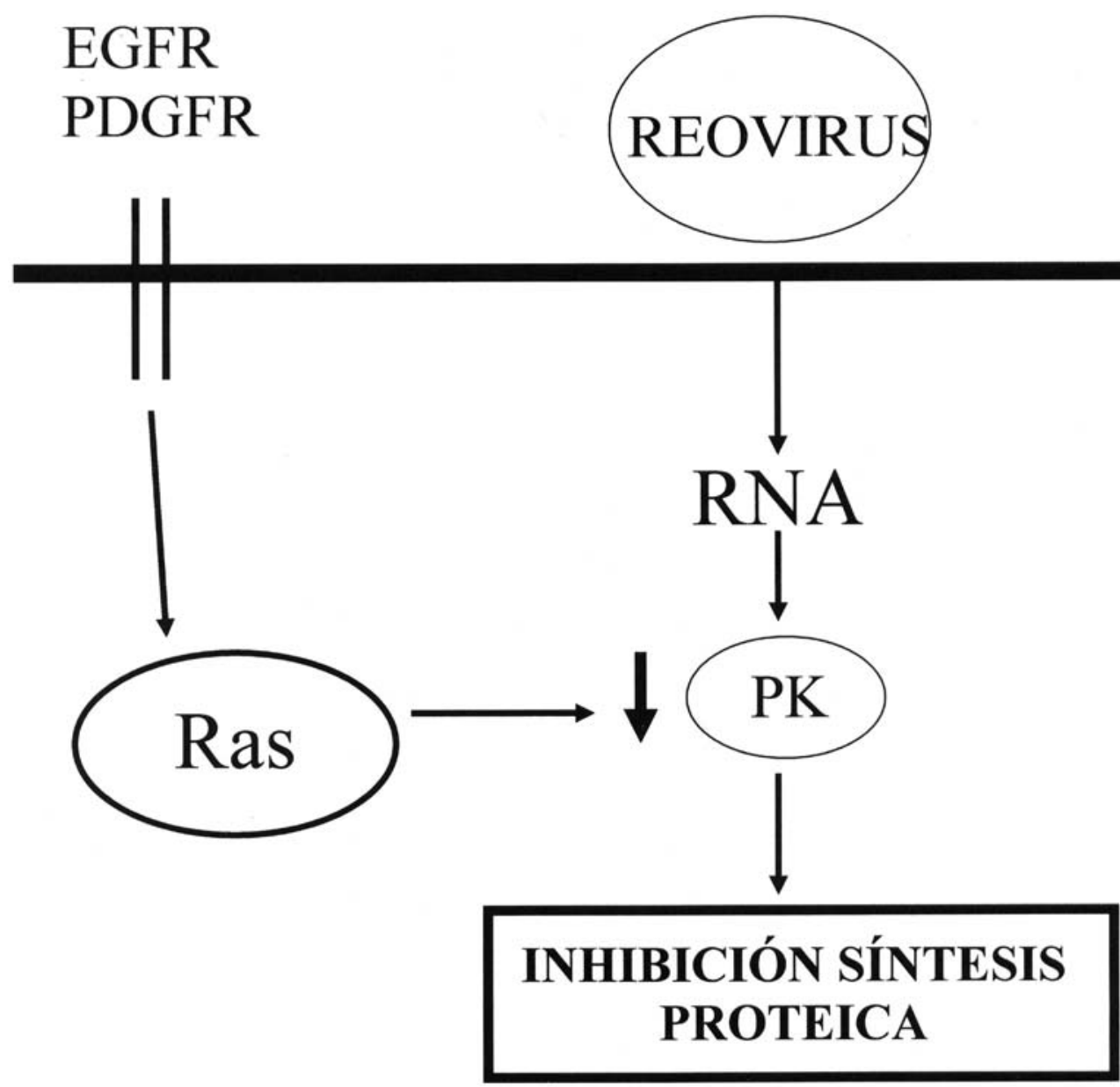

Figura 2. El ARN del virus activa una protein-kinasa de la célula huésped, la cual inhibe la síntesis proteica celular para proteger a la célula de la invasión viral. Si hay una sobrerregulación de la vía del Ras por si mismo o por sobrerregulación de los receptores EGFR oPDGFR- se interfiere la activación de la proteín-kinasa, impidiendo la inhibición de la síntesis proteica.

aumento significativo de la supervivencia, y en los análisis inmunohistoquímicos realizados sobre los tumores, se demostró la presencia de proteínas expresadas por adenovirus, lo que confirma la replicación viral intratumoral.

\section{Reovirus}

Los reovirus son una familia de RNA-virus asociada a infecciones leves o, en la mayoría de las ocasiones, asintomáticas. Ya en los años 70 se reconoció que estos virus mostraban una mayor citotoxicidad sobre las células transformadas que sobre las células normales ${ }^{28}$, pero no es hasta épocas recientes cuando se sabe cual es la causa de esta selectividad ${ }^{56}$. Como en los agentes modificados que hemos explicado con anterioridad, la selectividad en la infección hacia células tumorales radica en la alteración de los mecanismos de defensa genética que presentan estas células. Cuando el reovirus infecta células normales, el
ARN del virus activa una protein-kinasa de la célula huesped, la cual inhibe la síntesis proteica celular para proteger a la célula de la invasión viral. Sin embargo, la sobrerregulación de la vía del Ras interfiere con la activación de la protein-kinasa, por lo que aquellos tumores que presenten este tipo de alteración molecular serán infectados con mayor efectividad por los reovirus (Fig 2).

Ahora bien, las alteraciones en el gen Ras no son comunes entre los gliomas, por lo que podría pensarse que esta familia de virus no sería eficaz en la inmensa mayoría de los tumores gliales. Sin embargo, la sobreexpresión del receptor del epidermal growth factor (EGFR) y del receptor del platelet-derived growth factor (PDGFR) son alteraciones genéticas que se encuentran con frecuencia en los gliomas de alto grado, y estas alteraciones, conducen a la sobreexpresión del Ras y a la sobrerregulación de su señal. Por lo tanto, hipotéticamente, aquellos tumores gliales que presenten una sobreexpresión del EGFR o del PDGFR 
serán infectados y lisados preferentemente por los reovirus, siendo una infección relativamente inocua para los tejidos normales ${ }^{57,60}$.

El grupo que con mayor dedicación ha estudiado la utilidad de los reovirus en el tratamiento de los gliomas humanos ha sido el de la Universidad de Calgary. Este grupo ha realizado varios ensayos que muestran la marcada afinidad de estos virus hacia una línea celular de glioblastoma, la U87, que se caracteriza por sobreexpresar el PDGFR. En un ensayo realizado sobre ratones, se comprobó que se conseguían regresiones tumorales en el $65-80 \%$ de los casos. Este estudio se realizó sobre ratones inmunodeprimidos e inmunocompetentes, obteniendo buenos resultados en ambos casos, lo que indica que un sistema inmune competente no impide que el virus ataque a las células tumorales 9 . En un ensayo posterior realizado por el mismo grupo $^{66}$, se evaluó tanto in vitro como in vivo estos agentes, observando que el $83 \%$ de las células tumorales morían, obteniendo regresiones tumorales en los ratones a los que se les habían inoculado glioblastomas a nivel subcutáneo e intracerebral.

Con estos esperanzadores resultados en los ensayos preclínicos, se ha iniciado un ensayo clínico fase I/II dirigido por Coffey en el que se quiere probar la seguridad y la posible utilidad de este virus, que ha sido patentado bajo el nombre de Reolysin(C). Este ensayo esta siendo llevado a cabo en Calgary, en el Tom Baker Cancer Centre, aunque está pendiente de aprobación por parte de la FDA para poder extenderse a otros centros en USA. El agente esta siendo administrado en una triple dosis intratumoral, mediante una aguja guiada esterotáxicamente, en pacientes que padecen recurrencias de gliomas malignos.

\section{Poliovirus}

El poliovirus es un RNA-virus de la familia de los "Picornaviridae" que en la mayoría de las infecciones en humanos resulta asintomático, pero que en el 1-2\% de los casos puede llegar a afectar gravemente conduciendo a una poliomelitis paralítica. La neurovirulencia de este virus radica en la especificidad que presenta hacia la región de entrada al ribosoma de las células neurales, la denominada IRES (internal ribosome entry silo) ${ }^{22,24}$. El grupo de Gromeier y cols., de la Universidad Estatal de Nueva York, basándose en que las cepas usadas en la vacuna de Sabin se caracterizan por presentar mutaciones en sus elementos IRES, perdiendo así gran parte de su neurotoxicidad, crearon un nuevo mutante de poliovirus al que cambiaron la región IRES por otra del rinovirus humano tipo 2. Este nuevo mutante, cuya selectividad hacia las células neurales queda así disminuida, se denomina PV1(RIPO) ${ }^{22}$. Este grupo ha probado sobre ratones transgénicos y sobre primates el PV1(RIPO) $)^{32,23}$. Un problema que presenta este agente oncolítico es la necesidad de que la célula diana exprese el receptor CD155 -lo que no ocurre en todos los gliomas-, pues éste es el receptor que reconoce el virus para infectar la célula.

Otro método en el que se han empleado poliovirus como potenciales agentes oncolíticos es en la creación de los denominados replicons. En este caso, el genoma del poliovirus ha sido modificado mediante técnicas de ingeniería genética, sustituyendo el gen que codifica la cápside viral (P1) por otros genes de interés. Así, el genoma resultante al que se denomina replicon, es capaz de replicarse dentro de la célula a la que infecta, pero es incapaz de extenderse a otras células vecinas, pues carece de la maquinaria necesaria para llevar a cabo el proceso de encapsidación. El grupo de la Universidad de Alabama ha presentado resultados satisfactorios de ensayos preclínicos realizados sobre múltiples tipos de tumores, entre ellos tumores del SNC, a fin de realizar futuros ensayos clínicos ${ }^{2}$.

\section{Virus Vacuna (VV)}

El VV es un DNA-virus de la familia de los "poxviridae" que ha pasado a la historia de la medicina por ser el agente utilizado para combatir eficazmente la viruela, y con cuyo nombre se acuñó el término que popularmente define la inmunoprofiolaxis activa. Es un virus cuya infección es relativamente banal, pero induce una importante respuesta inmunológica y, en personas inmunocomprometidas, puede llegar a ser letal. El VV ha sido ampliamente estudiado como potencial agente oncolítico, llegando incluso a realizarse un ensayo fase III en pacientes con melanoma ${ }^{64}$, a los que se les administró una vacuna derivada del VV y de cuatro líneas celulares de melanoma. Aunque globalmente este ensayo no mostró diferencias en cuanto a la supervivencia, en un análisis retrospectivo se comprobó que en dos subgrupos de pacientes -los hombres de 44 a 57 con 1 a 5 ganglios positivos y los que presentaban un estadío I- había diferencias significativas.

En lo que a los gliomas hace referencia, Gridley y cols. ${ }^{21}$ probaron la posible utilidad de un VV recombinante al que se le hacía expresar el p53 (rVV-p53) junto con radiaciones ionizantes. Las células diana escogidas para probar esta combinación terapéutica fueron las C6 de glioma de rata, las cuales al carecer de p53 presentan cierta radiorresistencia. El rVV-p53 se administró parenteralmente en ratones a los que se les había inoculado subcutáneamente tumores formados por células C3. En el ensayo no hubo signos de toxicidad y, además, la regresión de los tumores respecto de un grupo control fue significativa. Basándose en esta idea, este mismo grupo probó el rVV-p53 en otras líneas celulares tanto humanas como de roedores, comprobando que en todas ellas se inducía la apoptosis y una disminución del crecimiento. Pero sorprendentemente, este estudio mostró 
que todas las líneas celulares respondían de igual forma, sin influir en su respuesta el status del p53 de la propia célula.

Este mismo grupo también ha estudiado la capacidad anticancerosa de otros VV recombinantes a los que se les han insertado otros genes diferentes. En un ensayo posterior, se comparó la efectividad antitumoral, tanto por separado como en combinación, de VV que expresaban el gen $\mathrm{p} 53$, el gen de la interleucina 2, el gen de la interleucina 12 y los genes de ambas interleucinas (rVV-p53, rVV-mIL2, rVV-mIL12 y rVV-2-12) . $^{8}$ Probando estos agentes sobre un modelo animal, se observó que utilizando las combinaciones rVV-p53/rVV-mIL2 ó rVV-p53/rVV-2-12 se obtenía una mejoría significativa respecto de los tratamientos con un único agente; sin embargo, utilizando la combinación rVV-p53/rVV-mIL2 no se obtenían mejores resultados que con el rVV-p53 en solitario. Pero el problema que plantean los virus a los que se les ha introducido genes que expresan interleucinas es la importante respuesta inmune que generan, la cual parece responsable tanto de la eficacia antitumoral como de la toxicidad?

\section{Parvovirus}

El último virus que ha entrado a formar parte de la lista de posibles agentes oncolíticos para el tratamiento de los gliomas es el parvovirus H-1 (PH1). Los parvovirus han sido objeto de estudio como potenciales instrumentos de terapia anticancerosa debido a su capacidad de prevenir la formación de tumores espontáneos o inducidos en ensayos animales, así como por estudios epidemiológicos en humanos que revelan la menor incidencia de ciertos cánceres en personas con serología positiva para esta familia de virus $^{52}$. El efecto oncosupresor del PH1 fue demostrado al ser evaluada su eficacia contra células tumorales humanas implantadas en ratones inmunodeprimidos ${ }^{12}$.

Con respecto a la posibilidad de utilizar el PH1 en el tratamiento de tumores cerebrales, Ohshima y cols. realizaron un primer ensayo en el que, infectando con $\mathrm{PH} 1$ células de la línea celular C6 de glioblastoma de rata "in vitro" e "in vivo" comprobaron que esta infección inducía un claro aumento de la apoptosis en las células $\mathrm{C}^{46}$. Más recientemente, Herrero y Calle y cols. han evaluado por primera vez la actividad oncolítica del PH1 en líneas celulares humanas de glioblastoma ${ }^{30}$. En este estudio se observó un eficiente poder de destrucción de células tumorales, así como la formación de partículas virales completas con potencial capacidad para infectar nuevas células tumorales vecinas.

\section{Conclusión}

Dado el sombrío pronóstico que muestran actualmente los gliomas, y la limitada capacidad de curación que presentan las terapias con las que hemos contado tradicionalmente, el gran desarrollo de nuevas técnicas de biología molecular se ha convertido en la principal puerta de esperanza hacia novedosas armas terapéuticas que incrementen sustancialmente la supervivencia de estos pacientes. Sin embargo, no es previsible que en un corto espacio de tiempo se puedan apreciar en el escenario clínico los frutos del esfuerzo investigador que se esta llevando a cabo. Por el momento, los resultados objetivables de ensayos clínicos en los que se han empleado terapias de genética molecular han sido desesperanzadores, pero es previsible que el incremento continuo de conocimientos mejore sustancialmente estos resultados.

En el futuro más inmediato deberán ser abordados varios aspectos del tratamiento con virus oncolíticos. En primer lugar, habrá que esperar a los resultados de los ensayos clínicos que están en marcha en humanos, y los que se planteen en un futuro, para evaluar la verdadera utilidad de los virus hasta ahora considerados como potencialmente eficaces contra los gliomas. Además, habrá que determinar cúal es el papel de estos virus dentro de posibles combinaciones terapéuticas, en las que otras técnicas -inmunoterapia, terapia génica, quimioterapia, radioterapia, cirugía...- puedan entrar en juego. Por último, habrá que seguir avanzando en el conocimiento de las bases genéticas de los gliomas para generar nuevos agentes que resulten cada vez más selectivos y eficaces.

\section{Bibliografía}

1. Alemany, R., Gómez-Manzano, C., Balague, C., Yung, W. K., Curiel, D. T., Kyritsis, et al.: Gene therapy for gliomas: molecular targets, adenoviral vectors, and oncolytic adenoviruses. Exp. Cell Res. 1999; 252: 1-12.

2. Ansardi, D.C., Porter, D.C., Jackson, C.A., Gillespie, G. Y.,Morrow, C.D.: RNA replicons derived from poliovirus are directly oncolytic for human tumor cells of diverse origins. Cancer Res. 2001; 61: 8470-8479.

3. Bischoff, J.R., Kirn, D.H., Williams, A., Heise, C., Horn, S., Muna, M., et al.: An adenovirus mutant that replicates selectively in p53-deficient human tumor cells. Science 1996; 274: 373-376.

4. Bluming, A.Z., Ziegler, J.L.: Regression of Burkitt's lymphoma in association with measles infection. Lancet 1971; 2: $105-106$.

5. Bousser, J., Zittoun, R.: Remission spontanee prolongee D-une leucemie lymphoide chromique. Nouv Rev Fr Hematol 2004; 5: 498-501.

6. Chambers, R., Gillespie, G.Y., Soroceanu, L., Andreansky, S., Chatterjee, S., Chou, J., et al.: Comparison of genetically engineered herpes simplex viruses for the treatment of brain tumors in a scid mouse model of human 
malignant glioma. Proc. Natl. Acad. Sci. U.S.A. 1995; 92: 1411-1415.

7. Chen, B., Timiryasova, T.M., Gridley, D.S., Andres, M. L., Dutta-Roy, R-Fodor, I.: Evaluation of cytokine toxicity induced by vaccinia virus-mediated IL-2 and IL-12 antitumour immunotherapy. Cytokine 2001; 15: 305-314.

8. Chen, B., Timiryasova, T.M., Haghighat, P., Andres, M. L., Kaiioka, E.FI., Dutta-Roy, R., et al.: Low-dose vaccinia virus-mediated cytokine gene therapy of glioma. J Immunother. 2001; 24: 46-57.

9. Coffey, M.C., Strong, J.E., Forsyth, P.A.,Lee, P.W.: Reovirus therapy of tumors with activated Ras pathway. Science 1998; 282: 1332-1334.

10. DePace, N.: Sulla scomparsa di un enorme cancro vegetante del col lo dell'utero senza cura chirurgica. Ginecologia 1912; 9: 82-89.

11. Dock, G.: Rabies virus vaccination in a patient with cervical carcinoma. Am J Med 1904; 127: 563.

12. Dupressoir, T., Vanacker, J.M., Cornelis, J.J., Duponchel, N., Rommelaere, J.: Inhibition by parvovirus H-1 of the formation of tumors in nude mice and colonies in vitro by transformed human mammary epithelial cells. Cancer Res. 1989; 49: 3203-3208.

13. Fueyo, J., Alemany, R., Gómez-Manzano, C., Fuller, G.N., Khan, A., Conrad, C.A., et al.: Preclinical characterization of the antiglioma activity of a tropismenhanced adenovirus targeted to the retinoblastoma pathway. J Nati. Cancer Inst. 2003; 95: 652-660.

14. Fueyo, J., Gómez-Manzano, C., Alemany, R., Lee, P. S., McDonnell, T.J., Mitlianga, et al.: A mutant oncolytic adenovirus targeting the $\mathrm{Rb}$ pathway produces antiglioma effect in vivo. Oncogene 2000; 19: 2-12.

15. Fueyo, J., Gómez-Manzano, C., Yung, W.K., Liu, T.J., Alemany, R., Bruner J.M., et al.: Suppression of human glioma growth by adenovirus-mediated Rb gene transfer. Neurology 1998; 50: 1307-1315.

16. Fulci, G., Chiocca, E.A.: Oncolytic viruses for the therapy of brain tumors and other solid malignancies: a review. Front Biosci. 2003; 8: e346-e360.

17. Ganly, I., Kirn, D., Eckhardt, G., Rodríguez, G.l., Soutar, D.S., Otto, R., et al.: A phase 1 study of Onyx-015, an E1B attenuated adenovirus, administered intratumorally to patients with recurrent head and neck cancer. Clin. Cancer Res. 2000; 6: 798-806.

18. Geoerger, B., Grill, J., Opolon, P., Morizet, J., Aubert, G., Lecluse, et al.: Potentiation of radiation therapy by the oncolytic adenovirus d11520 (ONYX-015) in human malignant glioma xenografts. Br J Cancer 2003; 89: 577-584.

19. Geoerger, B., Grill, J., Opolon, P., Morizet, J., Aubert, G., Terrier-Lacombe, et al.: Oncolytic activity of the E1B-55 $\mathrm{kDa}$-deleted adenovirus ONYX-015 is independent of cellular p53 status in human malignant glioma xenografts. Cancer Res. 2002; 62: 764-772.
20. Gómez-Manzano, C., Balague, C., Alemany, R., Lemoine, M.G., Mitlianga, P., Jiang, H., Khan, et al.: A novel E1A-E1B mutant adenovirus induces glioma regression in vivo. Oncogene 2004; 23: 1821-1828.

21. Gridley, D.S., Andres, M.L., Li, J., Timiryasova, T., Chen, B., Fodor, I.: Evaluation of radiation effects against C6 glioma in combination with vaccinia virus-p53 gene therapy. Int. J Oncol. 1998; 13: 1093-1098.

22. Gromeier, M., Alexander, L.,Wimmer, E.: Internal ribosomal entry site substitution eliminates neurovirulence in intergeneric poliovirus recombinants. Proc. Nati. Acad. Sci. U.S.A. 1996; 93: 2370-2375.

23. Gromeier, M., Bossert, B., Arita, M., Nomoto, A.,Wimmer, E.: Dual stem loops within the poliovirus internal ribosomal entry site control neurovirulence. J Virol. 1999; 73: 958-964.

24. Gromeier, M., Wimmer, E.: Viruses for the treatment of malignant glioma. Curr. Opin. Mol.T her. 2001; 3 : 503-508.

25. Hall, A.R., Dix, B.R., O'Carroll, S.J., Braithwaite, A.W.: p53-dependent cell death/apoptosis is required for a productive adenovirus infection. Nat. Med 1998; 4: 10681072.

26. Hamid, O., Varterasian, M.L., Wadler, S., Hecht, J. R., Benson, A., Galanis, E., et al.: Phase II trial of intravenous CI-1042 in patients with metastatic colorectal cancer. J Clin. Oncol. 2003; 21: 1498-1504.

27. Hansen, R.M., Libnoch, J.A.: Remision of chronic lymphocytic leukemia after smallpox vaccination. Arch Intern Med 1978; 138: 1137-1138.

28. Hashiro, G., Loh, P.C.,Yau, J.T.: The preferential cytotoxicity of reovirus for certain transformed cell lines. Arch Virol. 1977; 54: 307-315.

29. Hecht, J.R., Bedford, R., Abbruzzese, J.L., Lahoti, S., Reid, T.R., Soetikno, R.M., et al.: A phase I/II trial of intratumoral endoscopio ultrasound injection of ONYX015 with intravenous gemcitabine in unresectable pancreatic carcinoma. Clin.Cancer Res. 2003; 9: 555-561.

30. Herrero, Y.C., Cornelis, J.J., Herold-Mende, C., Rommelaere, J., Schlehofer, J.R.,Geletneky, K.: Parvovirus $\mathrm{H}-1$ infection of human glioma cells leads to complete viral replication and efficient cell killing. Int. J Cancer 2004; 109: $76-84$

31. Hunter, W.D., Maruza, R.L., Feigenbaum, F., Todo, T., Mineta, T., Yazaki, T., et al.: Attenuated replicationcompetent herpes simplex virus type I mutant G207: safety evaluation of intracerebral injection in nonhuman primates. J Virol. 1999; 73: 6319-6326.

32. Jang, S.K., Krausslich, H.G., Nicklin, M.J., Duke, G.M., Palmenberg, A.C., Wimmer, E.: A segment of the 5' nontranslated region of encephalomyocarditis virus RNA directs internal entry of ribosomes during in vitro translation. J Virol. 1988; 62: 2636-2643. 
33. Khuri, F.R., Nemunaitis, J., Ganly, I., Arseneau, J., Tannock, I.F., Romel, L., et al.: a controlled trial of intratumoral ONYX-015, a selectively-replicating adenovirus, in combination with cisplatin and 5-fluorouracil in patients with recurrent head and neck cancer. Nat. Med 2000; 6: 879-885.

34. Kucharczuk, J.C., Randazzo, B., Chang, M.Y., Amin, K.M., Elshami, A.A., Sterman, D.H., et al.: Use of a "replication-restricted" herpes virus to treat experimental human malignant mesothelioma. Cancer Res. 1997; 57: 466-471.

35. Lamfers, M.L., Grill, J., Dirven, C.M., van Beusechem, V.W., Geoerger, B., Van Den, B.J., et al.: Potential of the conditionally replicatioe adenovirus Ad5Delta24RGD in the treatment of malignant gliomas and its enhanced effect with radiotherapy. Cancer Res. 2002; 62: 5736-5742.

36. Lamont, J.P., Nemunaitis, J., Kuhn, J.A., Landers, S.A., McCarty, T.M.: A prospective phase II trial of ONYX-015 adenovirus and chemotherapy in recurrent squamous cell carcinoma of the head and neck (the Baylor experience). Ann. Surg. Oncol. 2000; 7: 588-592.

37. Lasner, T.M., Kesari, S., Brown, S.M., Lee, V.M., Fraser, N.W.,Trojanowski, J.Q.: Therapy of a murine model of pediatric brain tumors using a herpes simplex virus type1 ICP34.5 mutant and demonstration of viral replication within the CNS. J Neuropathol. Exp. Neurol. 1996; 55: 1259-1269.

38. Makower, D., Rozenblit, A., Kaufman, H., Edelman, M., Lane, M.E., Zwiebel, J., et al.: Phase II clinical trial of intralesional administration of the oncolytic adenovirus ONYX-015 in patients with hepatobiliary tumors with correlativa p53 studies. Clin. Cancer Res. 2003; 9: 693-702.

39. Markert, J. M., Malick, A., Coen, D. M.,Maruza, R. L.: Reduction and elimination of encephalitis in an experimental glioma therapy model with attenuated herpes simplex mutans that retain susceptibility to acyclovir. Neurosurgery 1993; 32: 603.

40. Markert, J. M., Medlock, A., Rabkin, S. D., Gillespie, G. Y., Todo, T., 1lunter, W. D., et al.: Conditionally replicating herpes simplex virus mutant G207 for the treatment of malignant glioma: results of the fase 1 trial. Gene Ther. 2000; 7: 859-866.

41. Maruza, R. L., Mal ick, A., Markert, J. M., Ruffner, K. L.,Coen, D. M.: Experimental therapy of human glioma by means of a geneticaly engineered virus mutant. Science 1991; 252: 856.

42. Mineta, T., Rabkin, S.D.,Maruza, R.L.: Treatment of malignant gliomas using ganciclovir-hypersensitive, ribonucleotide reductase-deficient herpes simplex viral mutant. Nat. Med. 2004; 1: 943.

43. Mullen, J.T., Tanabe, K.K.: Viral oncolysis. Oncolo- gist. 2002; 7: 106-119

44. Mulvihill, S., Warren, R., Venook, A., Adler, A., Randlev, B., Heise, C., et al.: Safety and feasibility of injection with an El B-55 kDa gene-deleted, replication-selectiva adenovirus (ONYX-015) into primary carcinomas of the pancreas: a phase I trial. Gene Ther. 2001; 8: 308-315.

45. Nemunaitis, J., Khuri, F., Ganly, I., Arseneau, J., Posner, M., Vokes, et al.: Phase II trial of intratumoral administration of ONYX-015, a replication-selective adenovirus, in patients with refractory head and neck cancer. J Clin. Oncol. 2001; 19: 289-298.

46. Ohshima, T., Iwama, M., Ueno, Y., Sugiyama, F., Nakajima, T., Fukamizu, et al.: Induction of apoptosis in vitro and in vivo by H-1 parvovirus infection. J Gen.Virol. 1998; 79 ( Pt 12): 3067-3071.

47. Papanastassiou, V., Rampling, R., Fraser, M., Petty, R., Hadley, D., Nicoll, J., et al.: The potential for efficacy of the modified (ICP 34.5(-)) herpes simplex virus HSV 1716 following intratumoural injection into human malignant glioma: a proof of principle study. Gene Ther. 2002; 9: 398-406.

48. Rampling, R., Cruickshank, G., Papanastassiou, V., Nicoll, J., Hadley, D., Brennan, D., et al.: Toxicity evaluation of replication-competent herpes simplex virus (ICP 34.5 null mutant 1716) in patients with recurrent malignant glioma. Gene Ther. 2000; 7: 859-866.

49. Randazzo, B.P., Kesari, S., Gesser, R.M., Alsop, D., Ford, J.C., Brown, S.M., et al.: Treatment of experimental intracranial murine melanoma with a neuroattenuated herpes simplex virus 1 mutant. Virology 1995; 211: 94 101.

50. Reid, T., Galanis, E., Abbruzzese, J., Sze, D., Wein, L.M., Andrews, J., et al.: Hepatic arterial infusion of a replication-selective oncolytic adenovirus (d11520): phase II viral, immunologic, and clinical endpoints. Cancer Res. 2002; 62: 6070-6079.

51. Ring, C.J.: Cytolytic viruses as potential anti-cancer agents. J Gen.Virol. 2002; 83: 491-502.

52. Rommelaere, J., Cornelis, J.J.: Antineoplastic activity of parvoviruses. J Virol. Methods 1991; 33: 233-251.

53. Shah, A.C., Benos, D., Gillespie, G.Y.,Markert, J.M.: Oncolytic viruses: clinical applications as vectors for the treatment of malignant gliomas. J Neurooncol. 2003; 65: 203-226.

54. Sinkovics, J.G., Horvath, J.C.: New developments in the virus therapy of cancer. Intervirology 1993; 36: 193-214.

55. Smith, R., Huebner, R.J.,Rowe, W.P.: Studies on the use of viruses in the treatment of carcinoma of the cervix. Cancer 1956; 9: 1218.

56. Strong, J.E., Coffey, M.C., Tang, D., Sabinin, P., Lee, P.W.: The molecular basis of viral oncolysis: usurpation of the Ras signaling pathway by reovirus. EMBO J 1998; 17: 33513362.

57. Strong, J.E., Tang, D., Lee, P.W.: Evidence that the epi- 
dermal growth factor receptor on host cells confers reovirus infection efficiency. Virology 1993; 197: 405-411.

58. Sundaresan, P., Hunter, W.D., Maruza, R.L.,Rabkin, S. D.: Attenuated replication-competent herpes simplex virus type 1 mutant G207: safety evaluation in mice. J Virol. 2000; 74: 3841 .

59. Suzuki, K., Fueyo, J., Krasnykh, V., Reynolds, P.N., Curiel, D.T., Alemany, R.: A conditionally replicative adenovirus with enhanced infectivity shows improved oncolytic potency. Clin. Cancer Res. 2001; 7: 120-126.

60. Tang, D., Strong, J.E.,Lee, P.W.: Recognition of the epidermal growth factor receptor by reovirus. Virology 1993; 197: 412-414.

61. Valyi-Nagy, T., Fareed, M.U., O'Keefe, J.S., Gesser, R.M., MacLean, A.R., Brown, S.M., et al.: The herpes simplex virus type 1 strain $17+$ gamma 34.5 deletion mutant 1716 is avirulent in SCID mice. J Gen.Virol. 1994; 75: 20592063.

62. Vasey, P.A., Shulman, L. N., Campos, S., Davis, J., Gore, M., Johnston, S., et al.: Phase I trial of intraperitoneal injection of the ElB-55-kd-gene-deleted adenovirus ONYX015 (d11520) given on days 1 through 5 every 3 weeks in patients with recurrent/refractory epithelial ovarian cancer. J Clin. Oncol. 2002; 20: 1562-1569.
63. Vladimirskaia, E.B.: A case of prolonged spontaneous remission in a patient with chronic lymphocytic leukemia. Probl Gematol Pereliv Krovi 2004; 7: 5 1-54.

64. Wallack, M.K., Sivanandham, M., Ditaranto, K., Shaw, P., Balch, C.M, Urist, M., et al.: Increased survival of patients treated with a vaccinia melanoma oncolysate vaccine: second interim analysis of data from a phase III, multi-institutional trial. Ann. Surg. 1997; 226: 198-206.

65. Weintraub, L.R.: Lynphosarcoma: Remission associated with viral hepatitis. JAMA 1969; 24: 1590-1591.

66. Wilcox, M.E., Yang, W., Senger, D., Rewcastle, N.B., Morris, D.G., Brasher, P.M., et al.: Reovirus as an oncolytic agent against experimental human malignant gliomas. J Natl. Cancer Inst. 2001; 93: 903-912

Arrese, I.; González, P.; Miranda, P.; Pérez-Núñez, A.; Pascual, B.; Lobato, R.D.: Tratamiento de los gliomas mediante virus oncolíticos: revisión de la literatura. Neurocirugía 2005; 16: 158-168.

Correspondencia postal: Ignacio Arrese Regañón. Servicio de Neurocirugía. Hospital Universitario 12 de Octubre. Avda de Córdoba s/n. 28041 Madrid. 